\title{
CONSERVAÇÃO PÓS-COLHEITA DE GUAVIRA \\ (Campomanesia adamantium Camb.) SOB DIFERENTES \\ REVESTIMENTOS E TEMPERATURAS \\ DE ARMAZENAMENTO ${ }^{1}$
}

\section{SILVANA DE PAULA QUINTÃO SCALON ${ }^{2}$, AYD MARY OSHIRO ${ }^{3}$, DAIANE MUGNOL DRESCH ${ }^{3}$}

RESUMO - Objetivou-se com este trabalho avaliar a conservação pós-colheita de guavira (Campomanesia adamantium Camb.) em diferentes revestimentos e temperaturas de armazenamento. Os frutos receberam os seguintes tratamentos: imersão em 1) carboxi metilcelulose a $1 \%(\mathrm{~m} / \mathrm{v})(\mathrm{CMC}) ; 2)$ pectina a $3 \% ; 3)$ pectina + cloreto de cálcio a $3 \%(\mathrm{~m} / \mathrm{v})$, e 4$)$ sem tratamento $(\mathrm{ST})$, todos embalados em polietileno de baixa densidade (PEBD) e armazenados por 0; 7; 14 e 21 dias em câmara B.O.D., nas temperaturas de 5; 10 e $15^{\circ} \mathrm{C}$. A menor perda de massa e acidez titulável foram observadas a $5^{\circ} \mathrm{C}$ e na cobertura pectina + cálcio. $\mathrm{O} \mathrm{pH}$ não variou entre as coberturas e manteve-se maior a $5{ }^{\circ} \mathrm{C}$. $\mathrm{O}$ teor de vitamina $\mathrm{C}$ foi maior sob efeito do revestimento de pectina + cálcio, com valores semelhantes aos iniciais a $5^{\circ} \mathrm{C}$ e $10^{\circ} \mathrm{C}$. Concluiu-se que as guaviras podem ser armazenadas por até 21 dias em temperatura de $5{ }^{\circ} \mathrm{C}$, revestidas com pectina + cálcio a $3 \%$.

Termos para indexação: Myrtaceae, carboximetilcelulose, pectina, atmosfera modificada.

\section{POSTHARVEST CONSERVATION OF guavira (Campomanesia adamantium Camb.) UNDER DIFFERENT COATING AND TEMPERATURES OF STORAGE}

\begin{abstract}
The objective of this study was to evaluate the post-harvest conservation of guavira (Campomanesia adamantium Camb.) in different coatings and temperatures. The fruit received the following treatments: immersion in 1) $1 \%$ carboxy methylcellulose (w/v) (CMC) 2) $3 \%$ pectin, 3) pectin $+3 \%$ calcium chloride (w/v) and 4) no treatment (ST) all packaged in low density polyethylene (LDPE) and stored for $0,7,14$ and 21 days in B.O.D. at temperatures of 5,10 and $15^{\circ} \mathrm{C}$. The lowest weight loss and titratable acidity were observed at $5^{\circ} \mathrm{C}$ and the coated with pectin + calcium. The $\mathrm{pH}$ did not vary between the coatings and kept higher than $5{ }^{\circ} \mathrm{C}$. The vitamin $\mathrm{C}$ content was higher under the influence of the coating of pectin + calcium with initial values similar to the 5 and $10{ }^{\circ} \mathrm{C}$. It was concluded that the guaviras can be stored for up to 21 days at $5{ }^{\circ} \mathrm{C}$, coated with pectin $+3 \%$ calcium.
\end{abstract}

Index terms: Myrtaceae, carboxy methylcellulose, pectin, modified atmosphere.

\section{INTRODUÇÃO}

A guavira (Campomanesia adamantium Camb.), espécie frutífera amplamente encontrada no bioma Cerrado, apresenta sabor e aroma característicos e agradáveis ao paladar, podendo ser consumida na forma in natura ou processada na forma de suco, sorvete, doce e licor (BAVIATI et al., 2004). Os frutos, em grande número por planta, estão disponíveis entre os meses de novembro e janeiro (VALLILO et al., 2006). Quando armazenados sob refrigeração, a vida útil é prolongada com manutenção dos teores de vitamina $\mathrm{C}$, fenóis totais e atividade antioxidante quando comparado ao armazenamento à temperatura ambiente, porém os frutos apresentam baixa conservação pós-colheita, que varia de 6 dias, quando sem nenhum revestimento, a 16 dias, quando tratados com 1-MCP associado ou não com atmosfera modificada (CAMPOS et al., 2012).

A modificação da atmosfera na conservação pós-colheita de frutos é sugerida como importante metodologia para reduzir a perda de água, além de proporcionar outros efeitos desejáveis, como a manutenção da firmeza e da cor através da alteração da composição de gases que circundam os frutos. $\mathrm{O}$ uso de atmosfera modificada, associado ao efeito da

\footnotetext{
'(Trabalho 149-12). Recebido em: 15-05-2012. Aceito para publicação em: 05-09-2012.

${ }^{2}$ Docente da Universidade Federal da Grande Dourados, Rodovia Dourados Itahum, Km 12, CEP: 79804970, Dourados-MS. E-mail: silvanascalon@ufgd.edu.br.

${ }^{3}$ Pós-graduandas em Agronomia/Produção Vegetal, Faculdade de Ciências Agrárias/ Universidade Federal da Grande Dourados, 79804970. Dourados-MS.E-mail: aydmow@gmail.com, daiamugnol@hotmail.com
} 
refrigeração evitam ou retardam os processos metabólicos envolvidos na ação das enzimas degradativas e oxidativas, e reduzem a respiração e a produção de etileno (CHITARRA; CHITARRA, 2005; CARVALHO FILHO et al., 2006; VIEITES et al., 2011; CAMPOS et al., 2012).

As embalagens propiciam a modificação da atmosfera e podem ser sintéticas, como as de polietileno de baixa densidade (PEBD), ou naturais e comestíveis. Embalagens comestíveis são utilizadas com finalidades protetoras, uma vez que auxiliam no controle da perda de massa pela transpiração, reduzindo as trocas gasosas pela respiração. Amariz et al. (2010) e Silva et al. (2011), em sua revisão, observaram que as coberturas comestíveis representam uma alternativa para aumentar a vida útil de frutas e hortaliças, e além de serem atóxicas, preservam a qualidade, retardando a deterioração, uma vez que regulam suas atividades metabólicas, melhorando a aparência do fruto armazenado, conferindo brilho como fator atraente para o consumidor. Geralmente, as coberturas são elaboradas a partir de proteínas, hidrocoloides, lipídeos, amilose, celulose, colágeno ou uma combinação dos mesmos. Observaram também que estas coberturas proporcionaram resultados positivos, especialmente para o controle da perda de massa e prolongamento da vida útil pós-colheita de morango, laranja, goiaba, pêssego, acerola e mexerica. Entretanto, não foram encontrados resultados na bibliografia consultada para a conservação de guavira

Assim, objetivou-se com este trabalho avaliar a conservação pós-colheita de guaviras em diferentes revestimentos e temperaturas de armazenamneto.

\section{MATERIAL E MÉTODOS}

Os frutos da guavira foram colhidos diretamente de plantas nativas em área de Cerrado, na fazenda Santa Madalena, sob coordenadas de $452 \mathrm{~m}$ de altitude de $22^{\circ} 08^{\prime} 25^{\prime}$ 'S e $55^{\circ} 08^{\prime} 17^{\prime}$ 'W na margem esquerda da rodovia BR $270, \mathrm{~km} 45$, que liga o município de Dourados e distrito de Itahum, em Mato Grosso do Sul.

A colheita foi realizada de modo aleatório, na quantidade de frutos por planta, porém com aspecto visual de frutos na maturidade fisiológica observada pela cor esverdeada da casca. Os mesmos foram transportados em caixas térmicas até o laboratório de Fisiologia Vegetal da Universidade Federal da Grande Dourados-MS, onde foram lavados em água corrente para reduzir o calor de campo e transporte. Em seguida, foram colocados em bancadas sanitizadas com hipoclorito $200 \mathrm{mg} \mathrm{L}^{-1}$ e ambiente climatizado a $20^{\circ} \mathrm{C}$, onde foram secos por 24 horas. Após esse período, procedeu-se à seleção para exclusão de frutos com coloração da casca e tamanho desuniformes, e com algum tipo de injúria, e em seguida foram imersos em solução de hipoclorito de sódio $200 \mathrm{mg} \mathrm{L}^{-1}$, por período de 15 minutos. $\mathrm{O}$ excesso foi escorrido sobre peneira de Nálion em temperatura ambiente.

Os frutos receberam os seguintes tratamentos: imersão em 1) carboxi metilcelulose a 1\% (CMC) $(\mathrm{m} / \mathrm{v}) ; 2)$ pectina a $3 \%($ PECT $)(\mathrm{m} / \mathrm{v}) ; 3)$ pectina + cloreto de cálcio a $3 \%(\mathrm{PECT}+\mathrm{Ca})(\mathrm{m} / \mathrm{v})$, e 4$)$ sem tratamento (ST), todos embalados em polietileno de baixa densidade (PEBD), e foram armazenados em câmara B.O.D., nas temperaturas de $5^{\circ} \mathrm{C}, 10^{\circ} \mathrm{C}$ e $15{ }^{\circ} \mathrm{C}$ e $85 \%$ UR, sob luz constante, e mantidos em períodos de armazenamento de $0 ; 7 ; 14$ e 21 dias. $\mathrm{O}$ experimento foi realizado em delineamento inteiramente casualizado, em um fatorial com 4 (revestimentos) × 3 (temperaturas) x 4 (períodos de armazenamento) e cinco repetições constituídas de uma bandeja de poliestireno expandido, com 40 frutos cada.

Em cada dia de armazenamento, foram avaliadas a perda de massa e, após despolpamento manual dos frutos, as análises químicas realizadas foram: $\mathrm{pH}$; as análises químicas realizadas foram: $\mathrm{pH}$; sólidos solúveis (SS, ${ }^{\circ}$ Brix) (IAL, 2008); acidez titulável (AT - mg de ácido cítrico 100 g-1 de polpa) e vitamina C (mg 100 $\mathrm{mg}^{-1}$ de polpa) (AOAC, 2000, modificado por BENASSI; ANTUNES, 1998).

Os resultados foram analisados pelo teste $\mathrm{F}$ e, havendo significância, as médias em função de revestimentos e temperaturas foram comparadas pelo teste de Tukey e em função de temperaturas e períodos de armazenamento, análise de regressão a $5 \%$ de probabilidade, utilizando o programa computacional SANEST.

\section{RESULTADOS E DISCUSSÃO}

Não houve interação tripla significativa entre revestimentos, temperaturas e período de armazenamento para as características avaliadas.

Para a perda de massa, observou-se efeito do período de armazenamento com as embalagens e do período com as temperaturas. As menores perdas de massa foram observadas nas guaviras revestidas com pectina e pectina com cálcio a $3 \%(3,86 \%$ e $3,28 \%$, respectivamente) (Figura 1a), sugerindo que estes revestimentos foram mais eficientes em atuar como barreira à perda de vapores de água.

A associação de cálcio com o biofilme de pectina parece ter favorecido a manutenção da tex- 
tura do fruto por conferir maior rigidez à estrutura da parede celular e matriz péctica, impedindo a perda de água ou a troca de gases com o meio externo. Meneghel et al. (2008), em sua revisão, observaram que a perda de água e as modificações na lamela média e na parede celular podem influenciar na textura e no amolecimento de frutos armazenados.

$\mathrm{O}$ recobrimento das guaviras com CMC proporcionou perda de massa próximo ao percentual dos frutos sem tratamento, semelhante ao observado por Amariz et al. (2010), que recobriram mangas 'Tommy Atkins' com combinações de CMC e dextrinas, sugerindo a baixa efetividade desse recobrimento na redução da perda de massa.

A temperatura de $5{ }^{\circ} \mathrm{C}$ reduziu a perda de massa, provavelmente, por ter diminuído com maior intensidade o metabolismo dos frutos e as trocas gasosas com o meio, reduzindo a atividade respiratória e, assim, favorecendo o aumento de vida útil de frutos armazenados quando comparado ao armazenamento a 10 e $15^{\circ} \mathrm{C}$ (Figura $\left.1 \mathrm{~b}\right)$.

Apesar de o pH expressar um parâmetro intrínseco ao fruto, os valores iniciais $(4,5)$ e finais $(3,4)$ indicaram que houve diminuição durante o período de armazenamento em todos os revestimentos e temperaturas (Figuras 2a e 2b), e essa mesma tendência também foi observada nas coberturas de pectina, com e sem cálcio, podendo esses resultados serem devidos ao estádio de maturação das frutas. A temperatura de $5^{\circ} \mathrm{C}$ proporcionou menor variação de $\mathrm{pH}$ (Figura 2b).

Valores semelhantes de $\mathrm{pH}$ foram observados para C. adamantium por Vallilo et al. (2006) e para C. xanthocarpa por Santos et al. (2009) com médias de 4,3 e 3,89, respectivamente.

O teor de SS inicial das guaviras revestidas encontrava-se em torno de $16,25^{\circ} \mathrm{Brix}$, apresentando diminuição em todos os revestimentos e temperaturas ao longo do período de armazenamento (Figuras $3 \mathrm{a}$ e $3 b$ ), porém sendo semelhante em todos os revestimentos avaliados. Quanto à temperatura, os menores teores foram observados nos frutos armazenados a 10 ${ }^{\circ} \mathrm{C}$ e $15^{\circ} \mathrm{C}$ (Figura $3 \mathrm{~b}$ ).

De maneira geral, a redução dos SSs pode estar relacionada com o estádio avançado de maturação dos frutos no início do armazenamento, pois espera-se que durante o amadurecimento ocorresse aumento de SS em decorrência da transformação dos polissacarídeos insolúveis em açúcares solúveis (CHITARRA; CHITARRA, 2005). A diminuição desses teores pode significar que os teores iniciais estão servindo de substrato para a senescência.

Ao caracterizar a diversidade genética desta mesma espécie, cujos frutos foram colhidos no mes- mo local deste experimento, Pelloso et al. (2008) também encontraram variação entre 12,77 a 16,33 ${ }^{\circ}$ Brix em frutos colhidos em 2007, em Mato Grosso do Sul. Melchior et al. (2006) observaram valores superiores de SS para essa mesma espécie em estádio de maturação verde levemente amarelado, encontrando variações entre 13,83 e $22,12^{\circ} \mathrm{Brix}$.

Quanto à AT, em todos os tipos de revestimento, houve aumento em seus valores de até 2,3 vezes em comparação com o início do armazenamento para as guaviras-testemunha e 1,52 vez para aquelas recobertas com pectina + cálcio (Figura $4 a$ ). $\mathrm{O}$ aumento no teor de AT acompanhou a variação do pH durante o período de armazenamento, sugerindo que compostos responsáveis (ácidos orgânicos) pela AT em frutos liberam íons de hidrogênio, contribuindo para caracterizar a elevação do $\mathrm{pH}$ nesse período. Silva et al. (2009) relataram que o teor de AT para C. pubescens, em torno de $1,5 \%$, indica pico climatérico, sendo esse valor maior que o obtido neste trabalho para $C$. adamantium.

$\mathrm{O}$ teor de AT aumentou nos frutos armazenados a $10{ }^{\circ} \mathrm{C}$ e $15{ }^{\circ} \mathrm{C}$, sendo maior aos 21 dias (Figura 4b). Ao final das avaliações, o revestimento pectina + cálcio e a temperatura de armazenamento de $5{ }^{\circ} \mathrm{C}$ proporcionaram o menor teor de AT de guaviras. Esse resultado pode ser devido à menor perda de água por transpiração nessa condição, o que proporcionou menor concentração dos solutos. $\mathrm{O}$ aumento da acidez pode ser atribuído também à liberação dos ácidos galacturônicos da parede celular que aumentam com o amadurecimento do fruto pela ação das enzimas pectinametilesterase e poligalacturonase (ALVES et al., 2000), sendo condizente com o alto teor de pectina detectado em guavira por Santos et al. (2009). Na presente pesquisa, a adição de pectina+cálcio associada à menor temperatura de armazenamento, provavelmente, contribuiu para manter a integridade da parede celular, retardando assim a liberação desse ácido, o que contribuiu para manter a AT mais baixa.

Os valores de AT observados neste trabalho encontram-se abaixo daqueles quantificados por Vallilo et al. (2006) para C. adamantium nativa, em São Paulo, e coletada em diferentes estádios de maturação, com média de $1,2 \mathrm{~g}$ de ácido cítrico 100 $\mathrm{g}^{-1}$, embora Santos et al. (2009) tenham observado

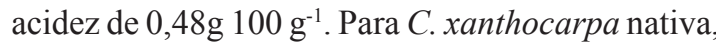
no Paraná, a AT foi em média de 1,92 em fruto verde; 1,49 em fruto de vez, e 1,45 g $100 \mathrm{~g}^{-1}$ ác. cítrico quando maduro (SANTOS, 2011). Campos et al. (2012) observaram AT em torno de $0,37{\mathrm{~g} 100 \mathrm{~g}^{-1}}^{-1}$ para Campomanesia sp.. Estas diferenças podem ser devidas às condições climáticas e a fatores genéticos. 
Em todos os revestimentos e temperaturas de armazenamento, a vitamina $\mathrm{C}$ aumentou ao longo dos dias de armazenamento (Figuras 5a e 5b). O revestimento com pectina + cálcio proporcionou maior teor de vitamina $\mathrm{C}$ em comparação aos demais. Observa-se, na literatura, que há relação direta entre o conteúdo de cálcio nos frutos com a firmeza e tempo de vida útil. Quando o conteúdo de cálcio no fruto é baixo, o metabolismo respiratório aumenta e acelera a maturação e a senescência (PRATELLA, 2003). Com a manutenção da vida útil pós-colheita, os frutos podem manter sua atividade metabólica e, assim, no decorrer do armazenamento, pode haver maior síntese de metabólitos intermediários que promovam a síntese de glucose-6-fosfato, o precursor imediato do ácido ascórbico, conforme observado por Linhares et al. (2007) em sua revisão.

Ressalta-se assim a importância do implemento do cálcio neste tipo de revestimento, pois, no armazenamento sem cobertura e sem cálcio, o teor da vitamina $\mathrm{C}$ foi menor nesse mesmo período. Não houve ajuste significativo para as médias de vitamina $\mathrm{C}$ nas temperaturas de 5 e $10^{\circ} \mathrm{C}$ (Figuras $5 \mathrm{~b}$ ), não havendo um padrão de comportamento dessa vitamina ao longo das avaliações nessa condição.

O efeito benéfico da refrigeração, associado à atmosfera modificada, foi demonstrado por Campos et al. (2012), que observaram maior conservação pós-colheita de Campomanesia sp. no armazenamento refrigerado a $11^{\circ} \mathrm{C}$, associado à atmosfera modificada +1 metilciclopropeno, havendo maior vida útil e teores elevados de sólidos solúveis, acidez titulável, vitamina $\mathrm{C}$, fenóis totais e atividade antioxidante, comparado ao armazenamento a 28 ${ }^{\circ} \mathrm{C}$, e observaram também que, nessas condições, os frutos se conservaram por até 16 dias , comparados aos frutos sem tratamento, que se mantiveram por apenas 6 dias.

Ressalta-se que o aumento da vitamina $\mathrm{C}$ em todos os tratamentos avaliados pode ser atribuído ao crescente aumento da perda de massa ao longo das avaliações, o que pode ter contribuído para sua concentração no suco celular. Entretanto, Carnelossi et al. (2004) relataram que o aumento da vitamina C em mangabas (Hancornia speciosa) "de vez" e maduras, armazenadas em bandejas de poliestireno por nove dias a $6{ }^{\circ} \mathrm{C}, 18{ }^{\circ} \mathrm{C}$ e $25^{\circ} \mathrm{C}$, ocorre devido, provavelmente, ao avanço das reações oxidativas durante o amadurecimento.

A guavira é naturalmente rica em vitamina $\mathrm{C}$, e as médias encontradas neste trabalho estão de acordo com Vallilo et al. (2006) e Santos et al. (2009), que encontraram média de $234 \mathrm{mg} 100 \mathrm{~g}^{-1}$ para C. adamantium e C. xanthocarpa, e com Silva et al. (2009), que relataram $246 \mathrm{mg} 100 \mathrm{~g}^{-1}$ para $C$. pubescens. Como os valores citados são referentes à caracterização do fruto in natura, sugere-se que as embalagens utilizadas nesta pesquisa tenham sido efetivas no armazenamento sob refrigeração e que o teor da vitamina $\mathrm{C}$ tenha sido proporcional à variação da perda de massa em câmara fria, onde houve menor variação da vitamina $C$. a)

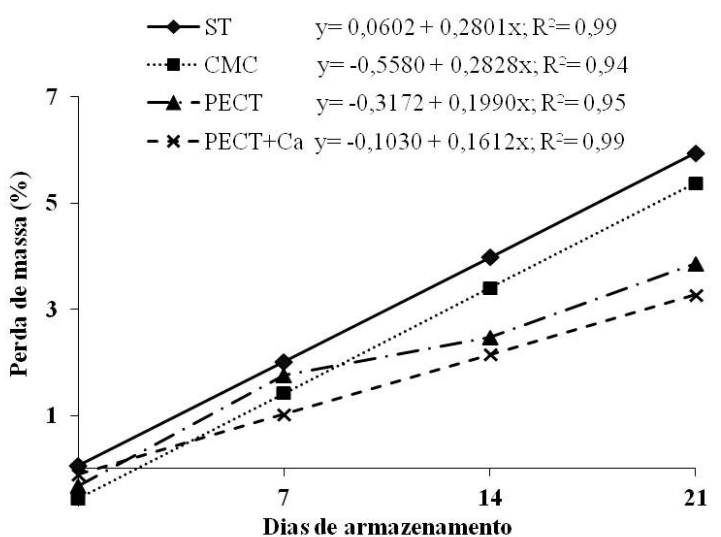

b)

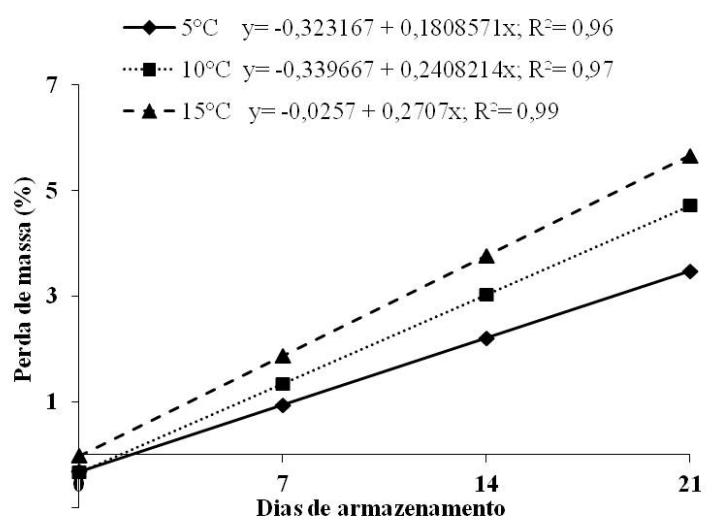

FIGURA 1 - Perda de massa de guavira (Campomanesia adamantium Camb.) armazenada sob diferentes revestimentos (a) e temperaturas (b). UFGD, 2010. (CMC = carboximetilcelulose a 1\%; PECT= Pectina a 3\%; PECT $+\mathrm{Ca}=$ Pectina com $\mathrm{CaCl}_{2}$ a $3 \%$ e $\mathrm{ST}=$ sem tratamento). 
a)

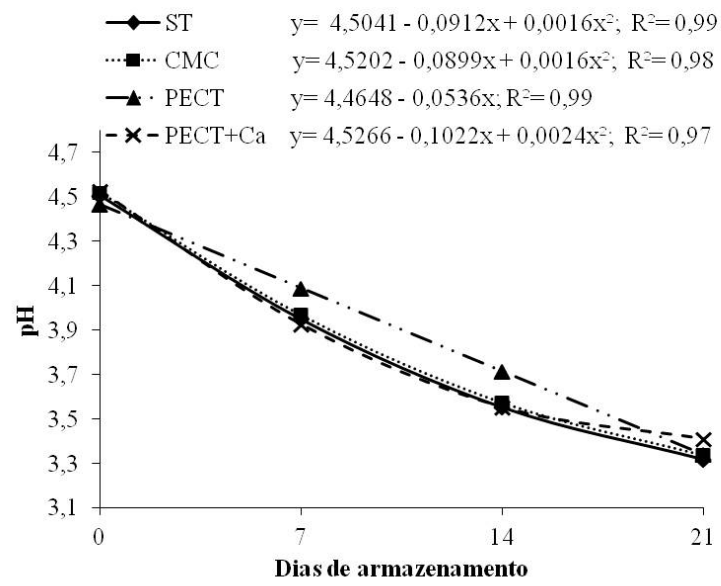

b)

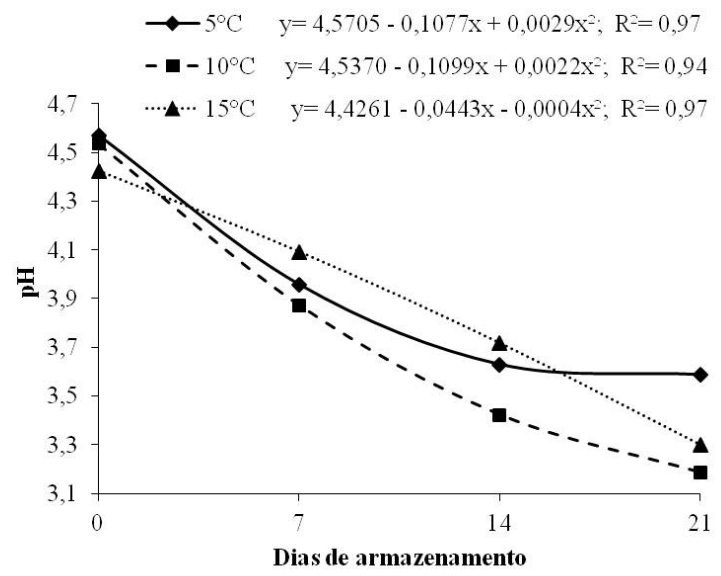

FIGURA 2 - pH de guavira (Campomanesia adamantium Camb.) armazenada sob diferentes revestimentos (a) e temperaturas (b). UFGD, 2010. (CMC= carboximetilcelulose a 1\%; PECT= Pectina a $3 \%$; $\mathrm{PECT}+\mathrm{Ca}=$ Pectina com $\mathrm{CaCl}_{2}$ a $3 \%$ e $\mathrm{ST}=$ testemunha).

a)

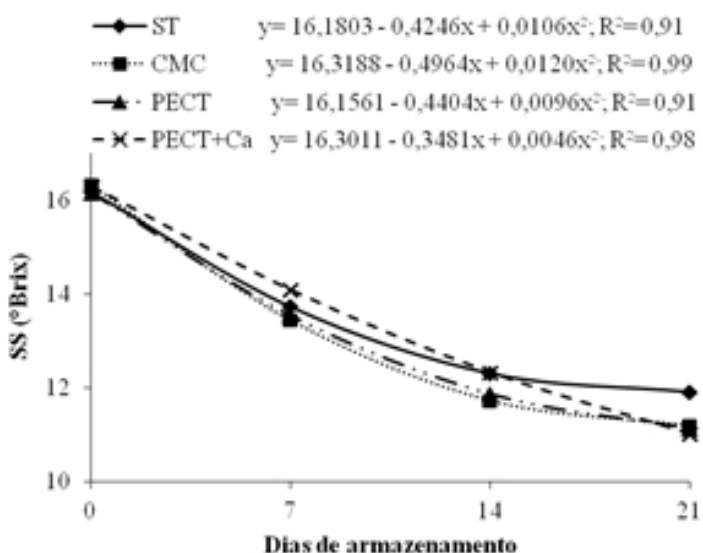

b)

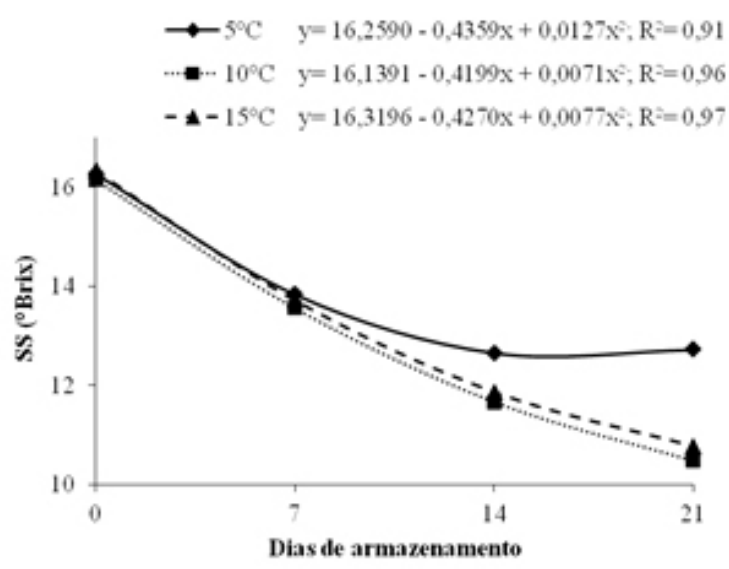

FIGURA 3 - Sólidos solúveis (SS) de guavira (Campomanesia adamantium Camb.) armazenada sob diferentes revestimentos (a) e temperaturas (b). UFGD, 2010. (CMC= carboximetilcelulose a 1\%; PECT= Pectina a $3 \%$; PECT $+\mathrm{Ca}=$ Pectina com $\mathrm{CaCl}_{2}$ a $3 \%$ e $\mathrm{ST}=$ testemunha). 


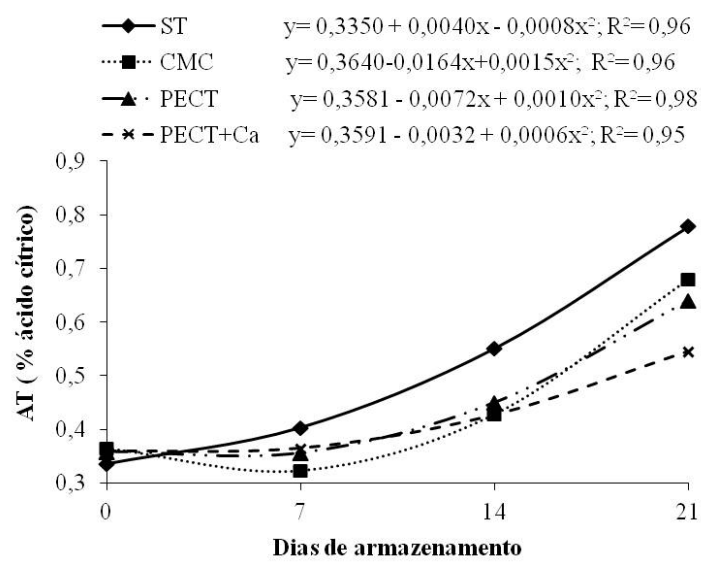

b)

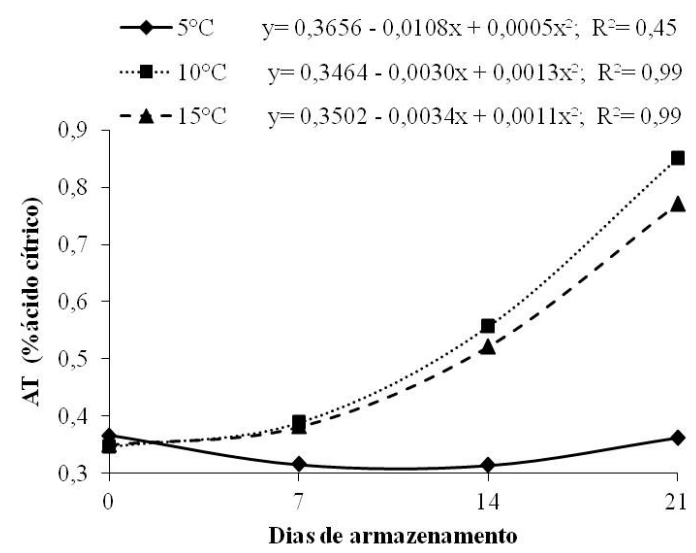

FIGURA 4 - Acidez titulável (AT) de guavira (Campomanesia adamantium Camb.) armazenada sob diferentes revestimentos (a) e temperaturas (b). UFGD, 2010. (CMC = carboximetilcelulose a 1\%, PECT= pectina a $3 \%, \mathrm{PECT}+\mathrm{Ca}=$ pectina $\operatorname{com} \mathrm{CaCl}_{2}$ a $3 \%$ e $\mathrm{ST}=$ testemunha).

a)

$$
\begin{array}{ll}
\longrightarrow \text { ST } & y=189,8716-10,8348 x+0,3684 x^{2} ; R^{2}=0,79 \\
\cdots \cdot \cdot \text { CMC } & y=\text { sem ajuste } \\
\longrightarrow \text { PECT } & y=188,0632-11,2937 x+0,5476 x^{2} ; R^{2}=0,68 \\
-\star \text { PECT }+ \text { Ca } & y=178,8673-9,0324 x+0,6595 x^{2} ; R^{2}=0,61
\end{array}
$$

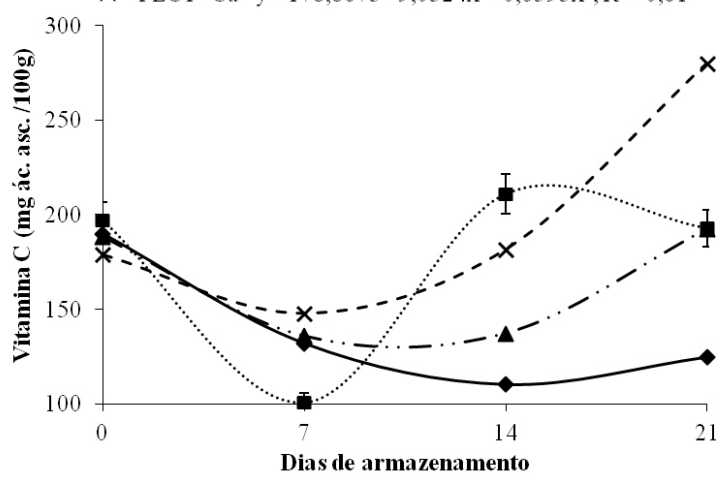

b)

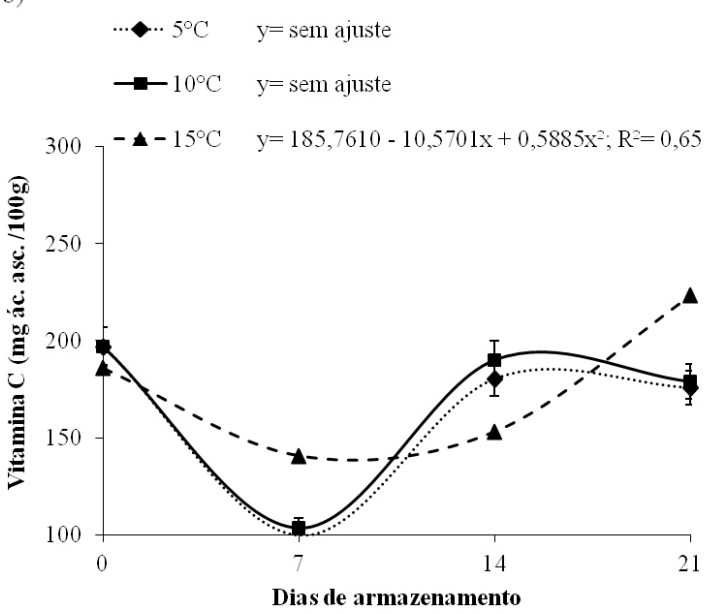

FIGURA 5 - Vitamina $\mathrm{C}$ de guavira (Campomanesia adamantium Camb.) armazenada sob diferentes revestimentos (a) e temperaturas (b). UFGD, 2010. (CMC = carboximetilcelulose a 1\%, $\mathrm{PECT}=$ pectina a $3 \%, \mathrm{PECT}+\mathrm{Ca}=$ pectina $\mathrm{com} \mathrm{CaCl}_{2}$ a $3 \%$ e $\mathrm{ST}=$ testemunha). 


\section{CONCLUSÃO}

1-Os frutos de guavira podem ser armazenadas por até 21 dias em temperatura de $5^{\circ} \mathrm{C}$. $3 \%(\mathrm{~m} / \mathrm{v})$.

2-A melhor cobertura é pectina + cálcio a

\section{REFERÊNCIAS}

ALVES, R.E.; FILGUEIRAS, H. A.C.; MOURA, C.F.H. Caracterização de frutas nativas da América latina. Jaboticabal: Funep, 2000. 66 p. (Série Frutas Nativas, 9)

AMARIZ, A.; LIMA, M.A.C.; TRINDADE, D.C.G.; SANTOS, A.C.N.; RIBEIRO, T.P. Recobrimentos à base de carboximetilcelulose e dextrina em mangas 'Tommy Atkins' armazenadas sob refrigeração. Ciência Rural, Santa Maria, v.40, n.10, p.2.1992.205, 2010 .

BAVIATI, M.; FARIAS, C.; CURTIUS, F.; BRASIL, L.M.; HORT, S.; SCHUSTER, L.; LEITE, S.N.; PRADO, S.R.T. Preliminary studies on Campomanesia xanthocarpa (Berg.) and Cuphea carthagenensis (Jacq.) J. F. Macbr. Aqueous extract: weight control and biochemical parameters. Journal of Ethnopharmacology, Maryland, v.93, p.385-389, 2004.

BENASSI, M. T. ; ANTUNES, A.J. A comparison of meta-phosphoric and oxalic acids as extractant solutions for the determination of vitamin $\mathrm{C}$ in selected vegetables. Arquivos de Biologia e Tecnologia, Curitiba, v.31, p.507-513,1998.

CAMPOS, R.P.; HIANE, P. A.; RAMOS, M.I.L.; RAMOS FILHO, M.M.; MACEDO, M.L. R.Conservação pós-colheita de guavira (Campomanesia sp.). Revista Brasileira de Fruticultura, Jaboticabal, v.34, n.1, p. 41-49, 2012.

CARNELOSSI, M.A.G.; TOLEDO, W.F.F.; SOUZA, D.C.L.S.; LIRA, M.L.; SILVA, G. F.; JALALI, V.R.; VIÉGAS, P.R.A. Conservação pós-colheita de mangaba (Hancornia speciosa Gomes). Ciência e Agrotecnologia, Lavras, v.28, n. 5, p. 1.119-1.125, 2004.

CARVALHO FILHO, C.D.; HONORIO, S.L.; GIL, J.M. Qualidade pós-colheita de cerejas cv. Ambrunés utilizando coberturas comestíveis. Revista Brasileira de Fruticultura, Jaboticabal, v.28, n.2, p.180-184, 2006.
CHITARRA, M.I.F.; CHITARRA, A.B. Pós-colheita de frutos e hortaliças: fisiologia e manuseio. 2.ed. Lavras: UFLA, 2005. 271p.

IAL - INSTITUTO ADOLFO LUTZ. Métodos físico-químicos para análise de alimentos São Paulo: Instituto Adolfo Lutz, 2008. p. 583-584.

LINHARES, L.A. ; SANTOS , C.D.; ABREU, C.M.P.; CORRÊA, A.D. Transformações químicas, físicas e enzimáticas de goiabas pedro sato tratadas na pós-colheita com cloreto de cálcio e 1-metilciclopropeno e armazenadas sob refrigeração. Ciência e Agrotecnologia, Lavras, v. 31, n. 3, p. 829-841, 2007.

MELCHIOR, S.J.; CUSTÓDIO, C.C.; MARQUES, T.A.; MACHADO NETO, N.B. Colheita e armazenamento de sementes de gabiroba (Campomanesia adamantium Camb. - Myrtaceae) e implicações na germinação. Revista Brasileira de Sementes, Viçosa, MG, v. 28, n.3, p.141-150, 2006.

MENEGHEL, R.F.A.; BENASSI, M.; YAMASHITA, F. Revestimento comestível de alginato de sódio para frutos de amora-preta (Rubus ulmifolius). Semina: Ciências Agrárias, Londrina, v. 29, n.3, p. $609-618,2008$.

PELLOSO, I. A. O.; VIEIRA, M. C.; ZÁRATE, N. A. H. Avaliação da diversidade genética de uma população de guavira (Campomanesia adamantium Cambess, O. Berg., Myrtaceae). Revista Brasileira de Agroecologia, Cruz Alta, v. 3, p.49-52, 2008. Suplemento especial

PRATELLA G.C. Note di biopatologia e tecnica di conservazione-trasporto dei frutti: l'effetto del calcio in post-raccolta. Rivista di Frutticoltura, Bologna, v.6, p.70-71, 2003.

SANTOS, M.S.; CARNEIRO, P.I.B.; WOSIACKI, G.L; PETKOWICZ, C.L.O.; CARNEIRO, E.B.B. Caracterização físico-química, extração e análise de pectinas de frutos de Campomanesia xanthocarpa $\mathrm{B}$. (Gabiroba). Semina: Ciências Agrárias, Londrina, v.30, n.1, p.101-106, 2009.

SANTOS, M.S. Impacto do processamento sobre as características físico-químicas, reológicas e funcionais de frutos da gabirobeira (Campomanesia xantocharpa Berg.). 2011. 148 f. Tese de Doutorado em Tecnologia de Alimentos - Setor de Tecnologia, Universidade Federal do Paraná, 2011 
SILVA, D. F. P. ;SIQUEIRA, D. L.; SANTOS, D.; MACHADO, D. L. M.; SALOMÃO, L. C.C. Recobrimentos comestíveis na conservação pós-colheita de 'Mexerica-do-Rio'. Revista Brasileira de Fruticultura, Jaboticabal, v.33, n.1, p. 357-362, 2011. Número especial.

SILVA, E.P.; VILAS BOAS, E.V.B.; RODRIGUES, L.J.; SIQUEIRA, H.H. Caracterização física, química e fisiológica de gabiroba (Campomanesia pubescens) durante o desenvolvimento. Ciência e Tecnologia de Alimentos, Campinas, v.29, n.4, p.803-809, 2009.

VALLILO, M.I.; LAMARDO, L.C.A.; GABERLOTTI, M. L.; OLIVEIRA, E.; MORENO, P. R.H. Composição química dos frutos de Campomanesia adamantium (Cambessédes) O. Berg.). Ciência e Tecnologia de Alimentos, Campinas, v.26, n.4, p. 805-810, 2006.
VIEITES, R.L.; DAIUTO, E.R.; MORAES, M.R.; NEVES, L.C.; CARVALHO, L.R. Caracterização físico-química, bioquímica e funcional da jabuticaba armazenada sob diferentes temperaturas. Revista Brasileira de Fruticultura, Jaboticabal, v.33, n.2, p.362-375, 2011. 